\title{
Chronic diseases and obesity risk: Analysis of Turkish data
}

\author{
Mustafa Ikızek, Serbest Hekim \\ Internal Medicine Clinic, Ankara, Turkey
}

Received: 2020-12-27.

Accepted: 2021-02-23

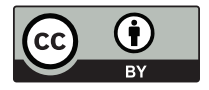

This work is licensed under a Creative Commons Attribution 4.0 International License

J Clin Med Kaz 2021; 18(2):31-38

Corresponding author:

Mustafa Ikizek.

E-mail: mustafaikizek@gmail.com;

\begin{abstract}
Objective: Obesity is a disease with multifactorial and complex etiology. While some chronic diseases are a risk factor for the development of obesity, obesity is associated with the incidence of many chronic diseases. This study aims to determine how much chronic diseases and various socio-demographic variables increase the risk of obesity [body mass index (BMI)].

Material and methods: In the study, the group of adults aged 18 and older was analyzed using a data set representing Turkey. The variables used in the analysis were obtained from the "TurkStat Health Survey" micro data set for 2016. In total, fifteen chronic disease types were analyzed using three models, seven binary regression analysis. The analyzes were carried out with 11,374 people.
\end{abstract}

Results: According to the results obtained in the basic model, bronchial asthma increases the risk of obesity by 1,22 times $(p<0,01)$, chronic bronchitis 1,31 times ( $p<0,001)$, essential hypertension 1,55 times ( $p<0,001)$, lumbar disc herniation 1,15 times $(p<0,001)$, diabetes mellitus 1,614 times $(p<0,001)$, and urinary incontinence 1,29 times $(p<0,001)$, compared to people without disease $(p<0,05)$. According to the results obtained in the disease model, bronchial asthma increases the risk of obesity by 1,29 times $(p<0,001)$, chronic bronchitis 1,29 times $(p<0,001)$, essential hypertension 1,661 times $(p<0,001)$, lumbar disc herniation 1,219 times $(p<0,001)$, diabetes mellitus 1,625 times $(p<0,001)$, and urinary incontinence 1,334 times ( $p<0,001$ ) compared to people without disease, stroke (0,234 times), cervical disc herniation (0,671 times) and liver failure $(0,502$ times) reduce the risk of obesity compared to people without disease $(p<0,05)$. In regression models based on both disease and health models, more chronic diseases increase the risk of obesity in women compared to men.

Conclusion: Diseases such as asthma, chronic bronchitis, diabetes, urinary incontinence, hypertension, and lumbar disc herniation were found to increase the risk of obesity. Diseases that increase the risk of obesity should be fought at the source.

Key words: chronic diseases, obesity, Turkey health survey, general health status, regression analysis

\section{Introduction}

Obesity, a major and widespread health problem, has become one of the major public health priorities in both developing and developed countries due to its increasing prevalence and association with numerous diseases $[1,2]$. While some chronic diseases are risk factors for the formation of obesity, obesity is associated with the prevalence of many chronic diseases. In some of the chronic diseases, this effect and relationship can be bi-directional. Cardiovascular disease, type-2 diabetes, hypertension, hyperlipidemia, various cancers, osteoarthritis and psychiatric diseases constitute the morbidity associated with increased obesity levels [2]. It is also an independent risk factor for various chronic diseases such as diabetes, hypertension and coronary heart disease [3].

The prevalence of obesity has been increasing dramatically in the world [4], and obesity causes significant problems in communities, health services, and individuals 
living with the disease [2]. According to 2016 data from the World Health Organization, it was determined that $39 \%$ of women and men aged 18 and over were overweight (BMI $>25)$ and $13 \%$ were obese (BMI $>30)$ [5]. According to TURDEP-II (The Turkish Epidemiology Survey of Diabetes, Hypertension, Obesity and Endocrine Disease Study-II; 2011), the increase in obesity prevalence in Turkey over 12 years was found to be $34 \%$ $(32,9$ to 44,2$)$ in women and $107 \%(13,2$ to 27,3$)$ in men. In the same study, the prevalence of obesity in the general population was found to be $31,2 \%[6,7]$.

One of the facts associated with obesity is the risk of sudden death. The risk of sudden death increases with increasing age and BMI [8-10]. Obesity is responsible for about $5 \%$ of all global deaths [11]. Today, more than 2,1 billion people, who make up about $30 \%$ of the global population, are overweight or obese. Obesity has a clearly measurable impact on health-related quality of life and produces significant direct and indirect costs. Because obesity is a potentially preventable disease, high health expenditures linked to obesity are considered "preventable health expenditures." The global economic impact caused by obesity is roughly $\$ 2$ trillion dollars, accounting for $2,8 \%$ of the global gross product [11]. It was reported that the direct cost of obesity to the UK as of 2002 was approximately one billion pounds and indirect costs of about two and a half billion pounds [12].

In this study, how chronic diseases and socio-demographic variables affect body mass index was examined. While the effect of socio-economic factors is more prominent in the basic model, how the general health status and the presence of chronic disease affect the body mass index in the health model was analyzed by logit regression. In addition, it was examined whether there was a difference by gender in each of the regression modules established.

\section{Material and methods}

The Turkish Health Survey (THS), which was conducted for the first time in 2008, is conducted every two years. THS 2016 data containing the information of more than 23 thousand people. In THS, participants were asked 349 questions and the data were coded with the help of the variable table. The survey consists of three main sections: Health variables related to 0-6 age, 7-14 age data and variables belonging to the adult group aged 15 and over. In the survey, information such as general health status, chronic diseases, functional competence in carrying out daily activities, personal care, use of health services, drug use, vaccines and measurements, tobacco-alcohol use and heightweight values were collected from individuals aged 15 and over. To collect information about health indicators, 9470 household addresses were selected and researched. The total number of observations in the data set is 23,606 . Since the data is limited to 18 years old and above, the sample consists of 11374 people. All analyzes were made with the data of 11374 people. THS data does not contain data for all chronic diseases. For example, there is no data on diseases such as AIDS and cancer. Since very few participants answered questions about some chronic diseases, these diseases were excluded from the analysis, Celiac, substance use and down syndrome variables were not included in the analysis due to numerical scarcity. Topics such as "low physical activity levels and malnutrition habits" [13], "bariatric surgery processes", [14], "methods and devices used in obesity treatment" [15], which had been widely studied in studies related to obesity, were not included in the scope of the study.
Discrimination of BMI by race [16] and data for BMI-based mortality [17] variables were not included in the analysis as they were not in THS raw data.

"Turkey Health Interview Survey was carried out by TurkStat in the year 2008 for the first time, and then it has been conducted every two years periodically. Health Survey derives many indicators on health including health conditions of infants, children and adults and also the utilization of health services, difficulties faced during daily activities and cigarette and alcohol using habits for individuals 15 years old and over. The survey included questions from members of the 0-14 age group, particularly those with data incompleteness to meet national needs, as well as modules proposed by the European Union Statistics Office for member and candidate countries. The research was applied to households with face-to-face interviews in four different surveys ("basic characteristics of household individuals", "0-6 age group", "7-14 age group" and "15+ age group"). Turkey Health Survey 2016 has carried out with selected 9470 households for estimation on total of Turkey." A more detailed description of the NHS methodology can be found elsewhere [43].

Fictional three models, 15 chronic disease data and seven binary regression analyzes were performed with sub-refractions. In the first model (basic model), the relationship between chronic diseases and general socio-demographic variables with BMI was examined. In the second model (health variables model), the relationship between disease and health status and chronic diseases with BMI was analyzed. Gender-based regression analysis was performed to determine whether the data of these two models varied by gender. Finally, the answer to the question of whether there was a relationship between the added socio-demographic variables and BMI was sought. In all models, the p-value less than 0,05 was considered as the limit of significance, and those whose p-value was significant were marked in red, The logical framework of the models is shown in the figure below (Figure 1).

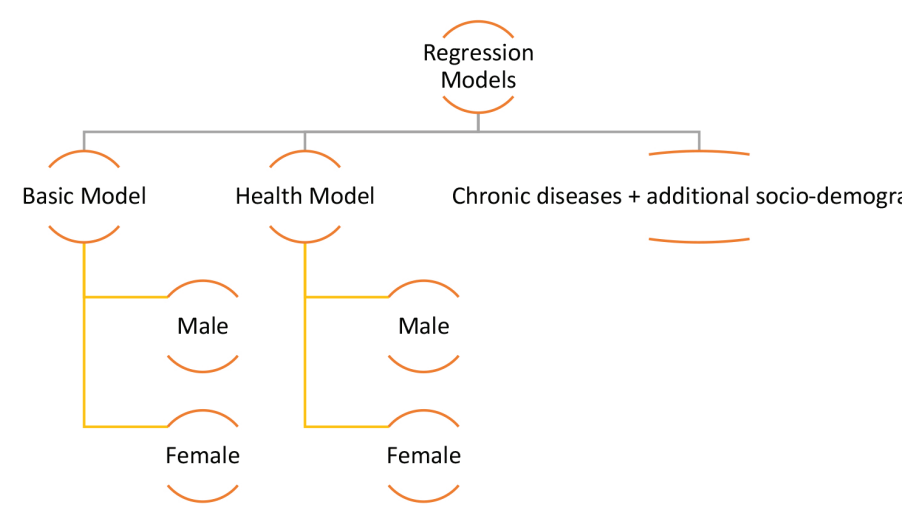

Figure 1. Three Models and Regression Models with Sub-Fractures

The data used in our research are publicly accessible data. The data does not contain any personal or corporate information. Therefore, it does not require ethics committee approval, informed consent form or institutional review board approval.

\section{Results}

Arithmetic mean, standard deviation and confidence intervals are given according to the ratio and number of demographic variables and the dependent variable of body mass index. Since the data is not missing value, the numerical grand total of all categories is 11374 people. The rate of women is 


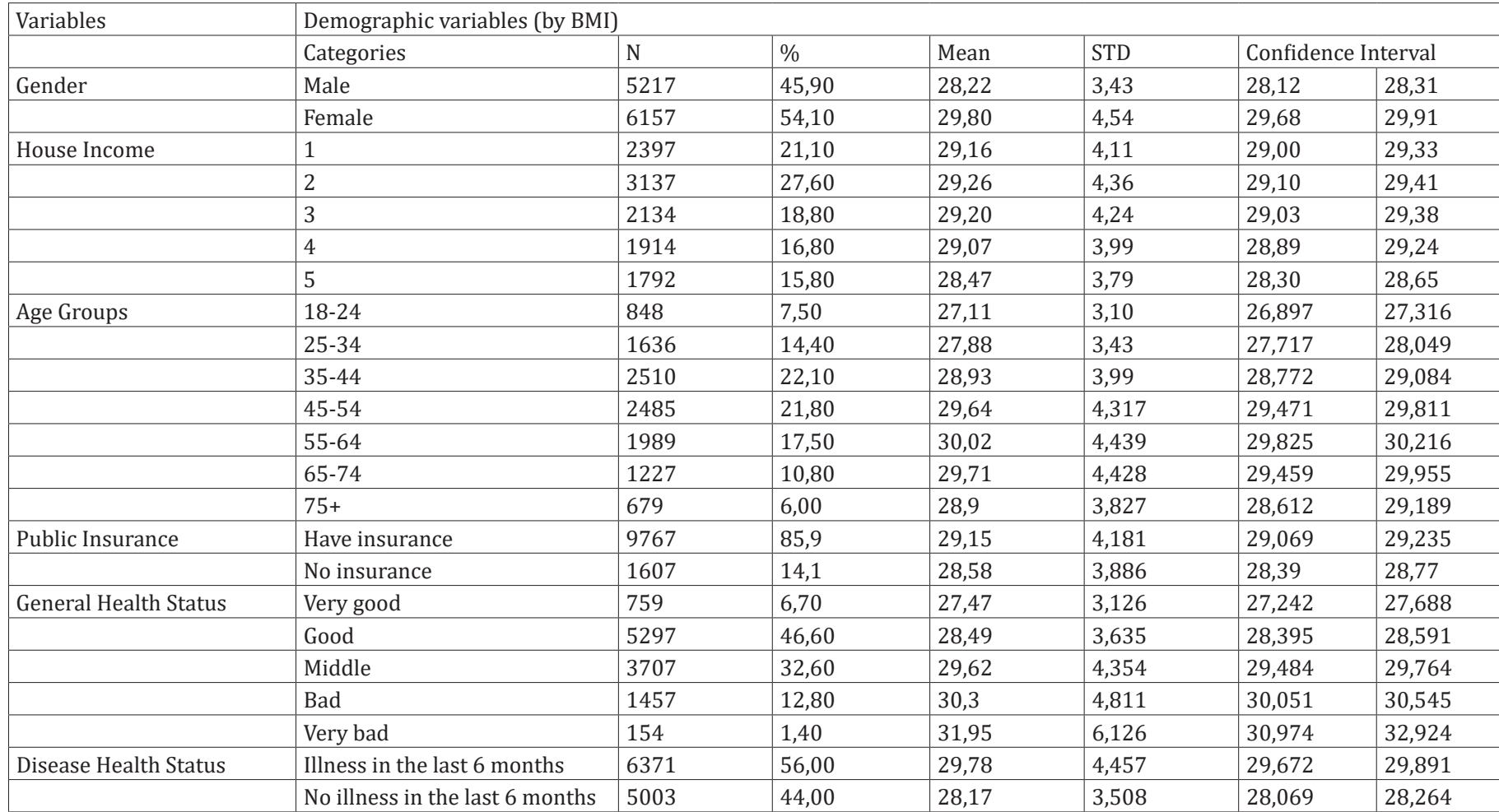

Table 2

Effect of Basic Model and Health Model on BMI

\begin{tabular}{|c|c|c|c|c|c|c|c|}
\hline \multirow[t]{2}{*}{ Variables } & \multicolumn{3}{|c|}{ BMI Basic Model N:11374 } & \multicolumn{4}{|c|}{ BMI Disease and Health Model N:11374 } \\
\hline & $\mathrm{B}$ & Sig, & $\mathrm{OR}^{*}$ & Variables & B & Sig, & OR \\
\hline Gender & $-0,544$ & 0,00 & 0,58 & GHS (VERY GOOD) & & 0,00 & \\
\hline Education & $-0,336$ & 0,00 & 0,715 & GHS (GOOD) & 0,887 & 0,00 & 2,427 \\
\hline Marital Status & $-0,024$ & 0,68 & 0,976 & GHS (MODERATE) & 0,411 & 0,00 & 1,509 \\
\hline Household Income & 0,005 & 0,77 & 1,005 & GHS (BAD) & 0,317 & 0,00 & 1,372 \\
\hline GHS & $-0,061$ & 0,07 & 0,941 & GHS (VERY BAD) & 0,281 & 0,01 & 1,324 \\
\hline DHS & 0,078 & 0,18 & 1,081 & DHS (1) & $-0,099$ & 0,10 & 0,906 \\
\hline Bronchial Asthma & 0,199 & 0,01 & 1,22 & Bronchial Asthma & 0,261 & 0,00 & 1,298 \\
\hline Chronic Bronchitis & 0,27 & 0,00 & 1,31 & Chronic Bronchitis & 0,257 & 0,00 & 1,293 \\
\hline Infarction & $-0,15$ & 0,24 & 0,86 & Infarction & $-0,211$ & 0,10 & 0,81 \\
\hline CHD & 0,051 & 0,52 & 1,052 & CHD & 0,011 & 0,89 & 1,011 \\
\hline Hypertension & 0,443 & 0,00 & 1,557 & Hypertension & 0,507 & 0,00 & 1,661 \\
\hline Stroke & $-0,712$ & 0,00 & 0,491 & Stroke & $-0,781$ & 0,00 & 0,458 \\
\hline Arthrosis & 0,294 & 0,00 & 1,342 & Arthrosis & 0,353 & 0,00 & 1,423 \\
\hline Lumbar Disc Herni-ation & 0,145 & 0,01 & 1,156 & Lumbar Disc Herni-ation & 0,198 & 0,00 & 1,219 \\
\hline Cervical Disc Herni-ation & $-0,256$ & 0,00 & 0,774 & Cervical Disc Herni-ation & $-0,183$ & 0,00 & 0,833 \\
\hline Diabetes Mellitus & 0,479 & 0,00 & 1,614 & Diabetes Mellitus & 0,485 & 0,00 & 1,625 \\
\hline Allergy & $-0,109$ & 0,09 & 0,896 & Allergy & $-0,089$ & 0,17 & 0,915 \\
\hline Liver failure & $-0,158$ & 0,27 & 0,854 & Liver failure & $-0,192$ & 0,18 & 0,825 \\
\hline Urinary incontinence & 0,26 & 0,00 & 1,297 & Urinary incontinence & 0,288 & 0,00 & 1,334 \\
\hline Chronic kidney & 0,014 & 0,86 & 1,014 & Chronic kidney & 0,002 & 0,98 & 1,002 \\
\hline Depression & $-0,023$ & 0,76 & 0,977 & Depression & 0,015 & 0,84 & 1,015 \\
\hline Alzheimer's & $-0,341$ & 0,08 & 0,711 & Alzheimer's & $-0,359$ & 0,06 & 0,698 \\
\hline 18-24 Age & & 0,00 & & 18-24 Age & & 0,00 & \\
\hline 25-34 Age & $-0,144$ & 0,31 & 0,866 & 25-34 Age & $-0,039$ & 0,78 & 0,962 \\
\hline 35-44 Age & 0,289 & 0,02 & 1,335 & 35-44 Age & 0,332 & 0,01 & 1,394 \\
\hline 45-54 Age & 0,74 & 0,00 & 2,096 & 45-54 Age & 0,79 & 0,00 & 2,203 \\
\hline 55-64 Age & 0,825 & 0,00 & 2,281 & 55-64 Age & 0,873 & 0,00 & 2,394 \\
\hline 65-74 Age & 0,802 & 0,00 & 2,23 & 65-74 Age & 0,837 & 0,00 & 2,309 \\
\hline $75+$ Age & 0,492 & 0,00 & 1,635 & $75+$ Age & 0,502 & 0,00 & 1,652 \\
\hline Constant & $-0,796$ & 0,00 & 0,451 & Constant & $-1,933$ & 0,00 & 0,145 \\
\hline Nagelkerke R Square & 0,124 & & & Nagelkerke R Square & 0,104 & & \\
\hline HL Sig & 0,429 & & & HL Sig & 0,498 & & \\
\hline \multicolumn{8}{|c|}{$\begin{array}{l}\text { GHS: General Health Status; DHS: Disease Health Status; CHD: Coronary Heart Disease; HL: Hosmer and Lemeshow; OR: Odds Ratio, CI: Confidens } \\
\text { Interval; }\end{array}$} \\
\hline \multicolumn{8}{|c|}{$\begin{array}{l}\text { * The statistically significant ones in the model are painted in red, For those whose } \mathrm{p} \text { value is less than } 0,05 \text {, the coefficient of } \mathrm{B} \text { is first evaluated, If the } \\
\text { coefficient is positive, the OR rate is interpreted as the increase of the dependent variable's risk, HL value greater than } 0,05 \text { indicates that the results of } \\
\text { the established multiple regression model can be trusted, }\end{array}$} \\
\hline
\end{tabular}


$54 \%$, the age range of the participants is between the $35-44$ age group and $85.9 \%$ of them have public health insurance. While the number of people with very bad general health condition is 154 , the number of those with bad health is 1457 . The rate of those who have had the disease in the last six months is $56 \%$ (Table 1).

In the next section binary regression analysis of basic and health model and gender-separated data of both models and regression analysis based on socio-demographic variables with chronic diseases will be shared.

Significant variables in the basic model were gender, educational status, age, bronchial asthma, chronic bronchitis, essential hypertension, stroke, arthrosis, lumbar disc herniation, cervical disc herniation, diabetes mellitus and urinary incontinence, Gender, educational status, stroke and cervical disc herniation decrease the frequency of obesity. The remaining variables increase the frequency of obesity (Table 2).

Significant variables in the health model were general health status, age, bronchial asthma, chronic bronchitis, essential hypertension, stroke, arthrosis, lumbar disc herniation, cervical disc herniation, diabetes mellitus and urinary incontinence, Stroke and cervical disc herniation reduce the frequency of obesity. The remaining variables increase the frequency of obesity (Table 2).

When the basic model was considered in terms of male gender, the variables that were significant in the model were education status, age, essential hypertension, arthrosis, cervical disc herniation and diabetes mellitus. Other remaining variables increase the risk of obesity (Table 3 ).

\begin{tabular}{|c|c|c|c|c|c|c|}
\hline & \multicolumn{3}{|c|}{ BMI Male N:5217 } & \multicolumn{3}{|c|}{ BMI Female N: 6157} \\
\hline & $\mathrm{B}$ & $\operatorname{Exp}(B)$ & Sig, & B & $\operatorname{Exp}(B)$ & Sig, \\
\hline 15-24 Age & & & 0,000 & & & 0,00 \\
\hline 25-34 Age & $-0,224$ & 0,799 & 0,366 & $-0,063$ & 0,939 & 0,73 \\
\hline 35-44 Age & 0,341 & 1,406 & 0,088 & 0,24 & 1,272 & 0,13 \\
\hline 45-54 Age & 0,788 & 2,199 & 0,000 & 0,671 & 1,956 & 0,00 \\
\hline 55-64 Age & 0,81 & 2,249 & 0,000 & 0,806 & 2,238 & 0,00 \\
\hline 65-74 Age & 0,838 & 2,313 & 0,000 & 0,753 & 2,123 & 0,00 \\
\hline $75+$ Age & 0,39 & 1,477 & 0,039 & 0,541 & 1,718 & 0,00 \\
\hline Education & $-0,287$ & 0,751 & 0,001 & $-0,411$ & 0,663 & 0,00 \\
\hline Marital Status & $-0,12$ & 0,887 & 0,286 & $-0,018$ & 0,982 & 0,81 \\
\hline Household Income & $-0,01$ & 0,99 & 0,701 & 0,016 & 1,016 & 0,45 \\
\hline GHS & $-0,063$ & 0,939 & 0,245 & $-0,064$ & 0,938 & 0,14 \\
\hline DHS & 0,109 & 1,116 & 0,230 & 0,093 & 1,098 & 0,24 \\
\hline Bronchial Asthma & $-0,046$ & 0,955 & 0,765 & 0,279 & 1,321 & 0,00 \\
\hline Chronic Bronchitis & 0,233 & 1,262 & 0,104 & 0,302 & 1,353 & 0,00 \\
\hline Infarction & $-0,126$ & 0,881 & 0,544 & $-0,121$ & 0,886 & 0,47 \\
\hline Coronary Heart Dis-ease & $-0,128$ & 0,88 & 0,347 & 0,154 & 1,166 & 0,12 \\
\hline Essential Hyperten-sion & 0,518 & 1,679 & 0,000 & 0,378 & 1,459 & 0,00 \\
\hline Stroke & $-0,446$ & 0,64 & 0,186 & $-0,882$ & 0,414 & 0,00 \\
\hline Arthrosis & 0,281 & 1,324 & 0,030 & 0,275 & 1,317 & 0,00 \\
\hline Lumbar Disc Herni-ation & 0,038 & 1,039 & 0,655 & 0,191 & 1,211 & 0,00 \\
\hline Cervical Disc Herni-ation & $-0,273$ & 0,761 & 0,010 & $-0,265$ & 0,767 & 0,00 \\
\hline Diabetes Mellitus & 0,341 & 1,406 & 0,001 & 0,548 & 1,729 & 0,00 \\
\hline Allergy & $-0,117$ & 0,89 & 0,338 & $-0,127$ & 0,881 & 0,11 \\
\hline Liver failure & 0,185 & 1,204 & 0,473 & $-0,321$ & 0,725 & 0,06 \\
\hline Urinary incontinence & 0,165 & 1,179 & 0,281 & 0,297 & 1,346 & 0,00 \\
\hline Chronic kidney & $-0,093$ & 0,912 & 0,500 & 0,059 & 1,06 & 0,54 \\
\hline Depression & 0,083 & 1,087 & 0,568 & $-0,057$ & 0,945 & 0,51 \\
\hline Alzheimer's & $-0,617$ & 0,54 & 0,131 & $-0,271$ & 0,762 & 0,23 \\
\hline Constant & $-1,279$ & 0,278 & 0,000 & $-0,751$ & 0,472 & 0,001 \\
\hline Nagelkerke R Square & 0,068 & & & 0,113 & & \\
\hline HL Sig & 0,636 & & & 0,471 & & \\
\hline
\end{tabular}

When the basic model was considered in terms of female gender, the variables that were significant in the model were age, education status, bronchial asthma, chronic bronchitis, essential hypertension, stroke, arthrosis, lumbar disc herniation, cervical disc herniation, diabetes mellitus and urinary incontinence. Other remaining variables increase the risk of obesity (Table 3).

When the disease model was considered in terms of the male gender, the variables that were significant in the model were age, general health status, essential hypertension, arthrosis, neck area problem and diabetes mellitus. Cervical disc herniation reduces the frequency of obesity and others increase the frequency (Table 4).

When the disease model was considered in terms of the female gender, the variables that were significant in the model were age, general health status, bronchial asthma, chronic bronchitis, essential hypertension, stroke, arthrosis, lumbar disc herniation, cervical disc herniation, diabetes mellitus, liver failure and urinary incontinence, Stroke, cervical disc herniation and liver failure decrease the frequency of obesity, others increase the frequency (Table 4). 


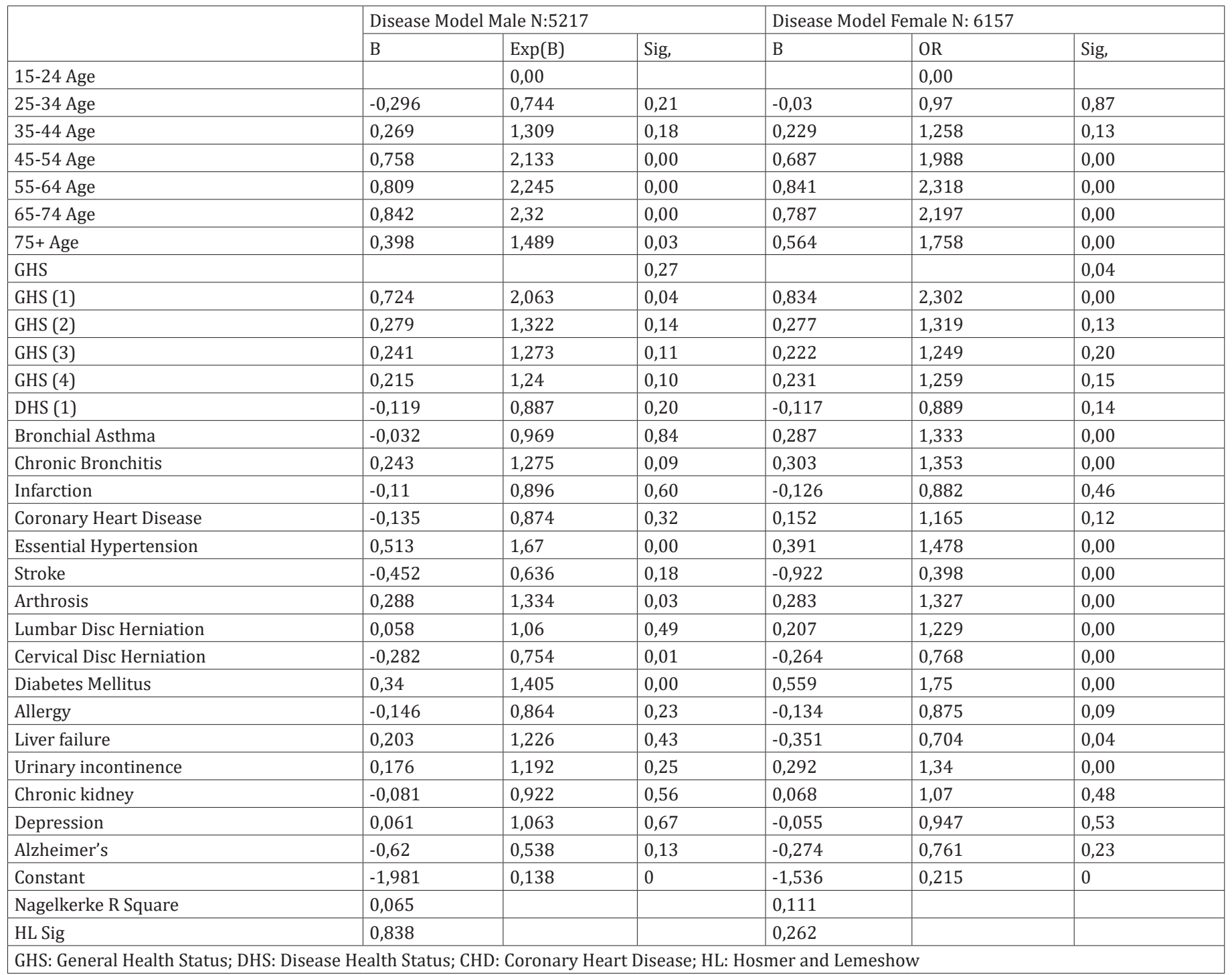

The variables that were significant in the last model, which was expanded by adding to chronic diseases, were gender, educational status, age, having social security, general health status, chronic bronchitis, essential hypertension, stroke, arthrosis, cervical disc herniation and diabetes mellitus, Gender, educational status, having social security, general health status, stroke and cervical disc herniation reduce the frequency of obesity (Table 5).

\section{Discussion}

If there is a data set representing the whole of Turkey and if it is stated that the study consists of data based on subjective statements and if it is proven before with logit regression models that socio-economic variables increase the risk of obesity, statements based on the presence and absence of chronic disease can also be subjected to logistic regression and the results of the analysis can be interpreted. Since the data which we have are variables obtained with a form of expression based on subjective judgments, the presence and name of the disease is actually a continuation of the negative response to the general state of health. If the general health status can be categorically included in the analysis, the name of the disease (the name of the chronic diseases) is actually nothing more than a negative subjective expression of the general health status.

In the data of the Turkish Health Survey for those with chronic disease, there are no data on many parameters affecting the course of the disease, such as the pre-illness state (in the context of the determinants of the disease) and the post-illness state (whether the medication is taken on time, bad habits and compliance with physician instructions). Therefore, as the medical history of the patients is not known, expressing the reasons for similarities and differences carries the danger of speculation. In order to avoid this risk, comparison dimensions have been made. Turkey Health Interview Survey is not a randomized controlled trial. It is neither a cohort nor a casecontrol study. Therefore, a general evaluation was made on the regression coefficients.

Obesity is a serious problem in Turkey, especially among women, The incidence of obesity increased from $21,7 \%$ in 1998 to $26,5 \%$ in 2013 [18] and to $33 \%$ in 2016. According to THS 2016 data, the frequency was $24,6 \%$ in men and $40,2 \%$ in women, (THS 2016 data)

In an article examining the studies conducted in developed countries on the subject of obesity, a negative correlation was found between the socioeconomic status and obesity (for women) in $63 \%$ of the 333 studies examined, [19], In this study, no significant relationship was found for both men and women.

Another factor closely associated with healthy lifestyles is education. It is reported that as the level of education experienced and acquired by individuals increases, the level of perception related to health increases in both men and women [20,21]. In all regression models established, the frequency of obesity 
Table 5

Chronic Diseases and the Effect of Added Socio-Demographic Variables on BMI

\begin{tabular}{|l|l|l|l|}
\hline \multicolumn{5}{|l|}{ BMI Binary N:7502 } & B & OR & Sig, \\
\hline & $-0,459$ & 0,632 & 0,00 \\
\hline Gender & $-0,204$ & 0,816 & 0,02 \\
\hline Treatment Costs-SGK & $-0,295$ & 0,744 & 0,00 \\
\hline Education & $-0,043$ & 0,958 & 0,58 \\
\hline Marital Status & 0,036 & 1,036 & 0,57 \\
\hline Working Status & $-0,019$ & 0,981 & 0,82 \\
\hline Business continuity & $-0,027$ & 0,974 & 0,23 \\
\hline Household Income & $-0,091$ & 0,913 & 0,04 \\
\hline GHS & 0,01 & 1,01 & 0,90 \\
\hline DHS & 0,083 & 1,087 & 0,42 \\
\hline Bronchial Asthma & 0,324 & 1,383 & 0,00 \\
\hline Chronic Bronchitis & $-0,039$ & 0,962 & 0,82 \\
\hline Infarction & $-0,129$ & 0,879 & 0,22 \\
\hline Coronary Heart Disease & 0,554 & 1,74 & 0,00 \\
\hline Essential Hypertension & $-0,652$ & 0,521 & 0,02 \\
\hline Stroke & 0,426 & 1,532 & 0,00 \\
\hline Arthrosis & 0,105 & 1,11 & 0,11 \\
\hline Lumbar Disc Herniation & $-0,304$ & 0,738 & 0,00 \\
\hline Cervical Disc Herniation & 0,436 & 1,546 & 0,00 \\
\hline Diabetes Mellitus & $-0,1$ & 0,905 & 0,24 \\
\hline Allergy & 0,032 & 1,033 & 0,86 \\
\hline Liver failure & 0,187 & 1,206 & 0,07 \\
\hline Urinary incontinence & $-0,068$ & 0,934 & 0,50 \\
\hline Chronic kidney & $-0,042$ & 0,959 & 0,67 \\
\hline Depression & $-0,28$ & 0,756 & 0,32 \\
\hline Alzheimer's & & 0,00 & \\
\hline 18-24 Age & 0,162 & 1,176 & 0,46 \\
\hline 25-34 Age & 0,595 & 1,813 & 0,00 \\
\hline 35-44 Age & 0,996 & 2,708 & 0,00 \\
\hline $45-54$ Age & 1,07 & 2,916 & 0,00 \\
\hline $55-64$ Age & 0,986 & 2,681 & 0,00 \\
\hline $65-74$ Age & 0,645 & 1,907 & 0,00 \\
\hline 75+ Age & $-0,865$ & 0,421 & 0,00 \\
\hline Constant & 0,101 & & \\
\hline Nagelkerke R Square & Lemeshow & & \\
\hline HL Sig & & \\
\hline GHS: General Health Status; DHS & \\
\hline Heart Disease; HL: Hosmer and & & \\
\hline
\end{tabular}

decreases as the level of education increases.

The findings in the literature are consistent with those obtained in our study that obesity is more common in married women than single women and that marriage is highly related to BMI $[22,23]$. According to THS 2016 data, $34 \%$ of married people were obese, while the frequency of those who were obese in the other group was 29,6\%, Despite this difference, no significant relationship was found in regression models.

In terms of age groups, the findings of our research on increasing the frequency of obesity as age increases are consistent with the findings in the literatüre $[24,25]$. No significant differences were found between the 25-34 age group and the 15-24 age group in terms of obesity frequency. It was determined that there was a significant difference in obesity frequency between the other age groups and the 15-24 age group. While the frequency of obesity increased with age increase in the age group of 25 to 65 , the rate of increase decreased despite the increase after 65 years of age.

According to the results of a study conducted on pregnant women in 2019, hypertension caused an increase in BMI value. In our study, parallel results were obtained. In the mentioned study, it was determined that hypertension increased the frequency of obesity by 0,59 times. In this study it was determined that it increased between 1,25 and 1,66 times in all regression models [26].

Numerous studies are showing that obesity increases the risk of bronchial [27-29]. There is also a study that the relationship and the effect between the two diseases are bilateral [30]. In this study, it was found that having bronchial asthma disease increased the frequency of obesity in various regression models by 1,11 to 1,29 times. In addition to numerous studies that obesity increases the risk of chronic bronchitis, there are also studies that chronic bronchitis increases the risk of obesity 1,8 times [31-33]. In this study, it was found that being a chronic bronchitis patient increased the frequency of obesity by 1,129 and 1,353 times in various regression models.

In addition to the many studies that obesity increases the frequency of diabetes mellitus, there is also a study that diabetes mellitus increases the frequency of obesity by 1,98 times [3436]. In this study, it was found that diabetes mellitus increased the frequency of obesity by 1,142 and 1,614 times in various regression models. In addition to numerous studies that obesity increases the frequency of arthrosis, there are also studies indicating that arthrosis increases the frequency of obesity by 1,21 times $[37,38]$. In this study, it was found that arthrosis increased the frequency of obesity by 1,133 and 1,423 times in various regression models.

In addition to numerous studies that obesity increases the frequency of lumbar disc herniation, there is also a study that lumbar disc herniation increases the frequency of obesity 1,22 to 1,34 times $[39,40]$. In this study, it was found that the lumbar disc herniation increased the frequency of obesity exclusively for women in various regression models by 1,156 and 1,229 times. Studies are indicating that the prevalence of urinary incontinence increases in parallel with the increase in BMI value [41-42]. In some cases, the disease increases the risk of obesity, while in other cases, obesity increases the risk of disease. In this study, it was also determined that urinary incontinence increased the frequency of obesity, especially for women, by 1,119 to 1,334 times in various regression models.

\section{Limitations}

A limited number of chronic diseases are included in the THS data. Therefore, only some of the chronic diseases were examined in our study. Since very few participants answered questions about some chronic diseases, these diseases were excluded from the analysis. Topics such as exercise and nutrition, which have been widely studied in studies on obesity as they would exceed the volume of the study.

\section{Conclusion}

As a result of analyses performed on Turkish Health Survey data, it was determined that only seven (bronchial asthma, chronic bronchitis, essential hypertension, arthrosis, lumbar disc herniation, diabetes mellitus, urinary incontinence) out of fifteen chronic diseases in the disease model increased the incidence of obesity and the frequency of obesity is higher in women by gender. Preventive interventions among women in Turkey should be declared. Women should be encouraged by physical activities and nutritional policies should be developed. Women should be informed on television and internet platforms about healthy nutrition and the management of chronic diseases. A healthy lifestyle should be encouraged for both genders, Turkey Obesity Prevention and Control Program aims to combat obesity. This program should be made known to the public. Reducing 
portions, salt consumption adjustments and the need for physical activity for health are the main elements of the program. The fight against obesity should be the main target of health policies because of its increasing prevalence and contribution to the causality of many secondary diseases. The results reported here found that a significant proportion of socioeconomic factors and chronic diseases increase the risk of obesity. These factors should be considered in the design of target group-specific measures for the prevention and treatment of obesity.

Disclosures: There is no conflict of interest for all authors.

\section{References}

1. Kuntz B, Lampert T. Socioeconomic factors and obesity. Deutsches Ärzteblatt International. 2010; 107(30):517. https://doi. org/10.3238/arztebl.2010.0517

2. Dixon JB. The effect of obesity on health outcomes. Molecular and cellular endocrinology. 2010; 316(2):104-108. https://doi. org/10.1016/j.mce.2009.07.008

3. Rippe JM, Crossley S, Ringer R. Obesity as a chronic disease: modern medical and lifestyle management. Journal of the American Dietetic Association. 1998; 98(10):9-15. https://doi.org/10.1016/S0002-8223(98)00704-4

4. Yusefzadeh H, Rahimi B, Rashidi ALI. Economic burden of obesity: A systematic review. Soc Health Behav. 2019; 2:7-12. https://doi. org/10.4103/SHB.SHB_37_18

5. World Health Organization. Physical status: The use of and interpretation of anthropometry. Report of a WHO Expert Committee. 1995

6. Satman I, Tutuncu Y, Gedik S, Dinccag N, Karsidag K, Yilmaz T at al. Diabetes epidemic in Turkey: Results of the second population based survey of diabetes and risk characteristics in Turkey (TURDEP-II), Poster: A-11-2498, 47th EASD Annual Meeting, 12-16 Sept 2011, Lisbon, Portugal. 2011

7. Oğuz S, Çamcı G, Arpacioğlu Y, Şeker M, Erbek H, Yurtdaş M. Bir aile sağlığı merkezine başvuran bireylerin obezite durumunun belirlenmesi. JAREN. 2019; 5(1):10-16. doi:10,5222/jaren.

8. Byers T. Overweight and mortality among baby boomers-now we're getting personal, New England Journal of Medicine. 2006; 355(8):758-760. https://doi.org/10.1056/NEJMp068156

9. Gu D, He J, Duan X, Reynolds K, Wu X, Chen J at al. Body weight and mortality among men and women in China. Jama. 2006; 295(7):776-783. https://doi.org/10.1001/jama.295.7.776

10. Jee SH, Sull JW, Park J, Lee SY, Ohrr H, Guallar E, Samet JM. Body-mass index and mortality in Korean men and women. New England Journal of Medicine. 2006; 355(8):779-787. https://doi.org/10.1056/NEJMoa054017

11. 11. Dobbs R, Sawers C, Thompson F, Manyika J, Woetzel J, Child P, at al. Overcoming obesity: An initial economic analysis. McKinsey Global Institute, 2014. 2016.

12. Tigbe WW, Briggs AH, Lean ME. A patient-centred approach to estimate total annual healthcare cost by body mass index in the UK Counterweight programme. International journal of obesity. 2013; 37(8):1135-1139. https://doi.org/10.1038/ijo.2012.186

13. Leyk D, Rüther T, Wunderlich M, Heiß A, Küchmeister G, Piekarski C, Löllgen, H. Sporting activity, prevalence of overweight, and risk factors: Cross-sectional study of more than 12500 participants aged 16 to 25 years. Deutsches Ärzteblatt International. 2008; 105(46):793. https://doi.org/10.3238/arztebl.2008.0793

14. DeMaria EJ. Bariatric surgery for morbid obesity. New England Journal of Medicine. 2007; 356(21):2176-2183. https://doi. org/10.1056/NEJMct067019

15. Kagan J, Dann M, Fluet G, Ikramuddin S, Swain P, Thomas R, Wilmore M. US. Patent Application No, 11/025,364. 2005.

16. Stevens J, Plankey MW, Williamson DF, Thun MJ, Rust PF, Palesch Y, O'Neil PM. The body mass index-mortality relationship in white and African American women. Obesity research. 1998; 6(4):268-277. https://doi.org/10.1002/j.1550-8528.1998.tb00349.x

17. Khalooeifard R, Djafarian K, Safabakhsh M, Rahmani J, Shab-Bidar S. Dose-Response Meta-Analysis of the Impact of Body Mass Index on Mortality in the Intensive Care Unit. Nutrition in Clinical Practice. 2020. https://doi.org/10.1002/ncp.10473

18. Santas F, Santas G. Obesity among Women in Turkey. Iranian Journal of Public Health. 2018; 47(5):682-688.

19. McLaren L. Socioeconomic status and obesity. Epidemiologic reviews. 2007; 29(1):29-48. https://doi.org/10.1093/epirev/mxm001

20. Arendt JN. Does education cause better health? A panel data analysis using school reforms for identification. Economics of Education review. 2005; 24(2):149-160. https://doi.org/10.1016/j.econedurev.2004.04.008

21. Biswas RK, Kabir E, Khan HT. Socioeconomic transition and its influence on body mass index (BMI) pattern in Bangladesh. Journal of evaluation in clinical practice. 2019; 25(1):130-141. https://doi.org/10.1111/jep.13028

22. Malcolm M, Kaya I. Selection works both ways: BMI and marital formation among young women. Review of Economics of the Household. 2016; 14(2):293-311. https://doi.org/10.1007/s11150-014-9247-8

23. Lipowicz A, Gronkiewicz S, Malina RM. Body mass index, overweight and obesity in married and never married men and women in Poland. American Journal of Human Biology: The Official Journal of the Human Biology Association. 2002; 14(4): 468-475. https:// doi.org/10.1002/ajhb.10062

24. Norman P, Fraser L. Self-reported general health and Body Mass Index: a U-shaped relationship? Public Health. 2013; 127(10):938-945. https://doi.org/10.1016/j.puhe.2013.07.003

25. Dehghanizade J, Najafipour F. Effects of a two-month training period on soldiers' general health, social physique anxiety, and body mass index. Journal of Archives in Military Medicine. 2016; 4(1). https://doi.org/10.5812/jamm.33430

26. Gasse C, Boutin A, Demers S, Chaillet N, Bujold E. Body mass index and the risk of hypertensive disorders of pregnancy: the great obstetrical syndromes (GOS) study. The Journal of Maternal-Fetal \& Neonatal Medicine. 2019; 32(7):1063-1068. https://doi.org/1 0.1080/14767058.2017.1399117

27. Khalid F, Holguin F. A review of obesity and asthma across the life span. Journal of Asthma. 2018; 55(12):1286-1300. https://doi.org/ $10.1080 / 02770903.2018 .1424187$

28. Patidar V, Tandon S, Nagdeote ST, Sharma D. Effect of BMI on Bronchial Asthma in Indian Adults. People. 2018; 11(1):1. 
29. Jesus JPVD, Lima-Matos AS, Almeida PCA, Lima VB, Mello LMD, Souza-Machado, A, Cruz ÁA. Obesity and asthma: clinical and laboratory characterization of a common combination. Jornal Brasileiro de Pneumologia. 2018; 44(3):207-212. https://doi.org/10.1590/ s1806-37562017000000034

30. Baffi CW, Winnica DE, Holguin F. Asthma and obesity: mechanisms and clinical implications. Asthma research and practice. 2015; 1(1):1. https://doi.org/10.1186/s40733-015-0001-7

31. Guerra S, Sherrill DL, Bobadilla A, Martinez FD, Barbee RA. The relation of body mass index to asthma, chronic bronchitis, and emphysema. Chest. 2002; 122(4):1256-1263. https://doi.org/10.1378/chest.122.4.1256

32. Yang L, Zhou M, Smith M, Yang G, Peto R, Wang J at al. Body mass index and chronic obstructive pulmonary disease-related mortality: a nationally representative prospective study of 220000 men in China. International journal of epidemiology. 2010; 39(4):1027-1036. https://doi.org/10.1093/ije/dyq051

33. Kvamme JM, Wilsgaard T, Florholmen J, Jacobsen BK. Body mass index and disease burden in elderly men and women: the Tromsø Study. European journal of epidemiology. 2010; 25(3):183-193. https://doi.org/10.1007/s10654-009-9422-z

34. Bays HE, Chapman RH, Grandy S, SHIELD Investigators' Group. The relationship of body mass index to diabetes mellitus, hypertension and dyslipidaemia: comparison of data from two national surveys. International journal of clinical practice. 2007; 61(5):737-747. https://doi.org/10.1111/j.1742-1241.2007.01336.x

35. Nguyen NT, Magno CP, Lane KT, Hinojosa MW, Lane JS. Association of hypertension, diabetes, dyslipidemia, and metabolic syndrome with obesity: findings from the National Health and Nutrition Examination Survey, 1999 to 2004. Journal of the American College of Surgeons. 2008; 207(6):928-934. https://doi.org/10.1016/j.jamcollsurg.2008.08.022

36. Feng J, Chen Q, Yu F, Wang Z, Chen S, Jin Z at al. Body mass index and risk of rheumatoid arthritis: a meta-analysis of observational studies. Medicine. 2016; 95(8). https://doi.org/10.1097/MD.0000000000002859

37. Lu B, Hiraki LT, Sparks JA, Malspeis S, Chen CY, Awosogba JA at al. Being overweight or obese and risk of developing rheumatoid arthritis among women: a prospective cohort study. Annals of the rheumatic diseases. 2014; 73(11):1914-1922. https://doi.org/10.1136/ annrheumdis-2014-205459

38. Heuch I, Heuch I, Hagen K, Zwart JA. Body mass index as a risk factor for developing chronic low back pain: a follow-up in the NordTrøndelag Health Study. Spine. 2013; 38(2):133-139. https://doi.org/10.1097/BRS.0b013e3182647af2

39. DePalma MJ, Ketchum JM, Saullo TR. Multivariable analyses of the relationships between age, gender, and body mass index and the source of chronic low back pain. Pain Medicine. 2012; 13(4):498-506. https://doi.org/10.1111/j.1526-4637.2012.01339.x

40. Mommsen S, Foldspang A. Body mass index and adult female urinary incontinence. World journal of urology. 1994; $12(6): 319-322$. https://doi.org/10.1007/BF00184112

41. Demirci N, Aba YA, Süzer F, Karadağ F, Ataman H. 18 yaş üstü kadınlarda üriner inkontinans ve yaşam kalitesine etkileri. Fırat Sağllk Hizmetleri Dergisi. 2012; 7(19): 23-37.

42. Aune D, Mahamat-Saleh Y, Norat T, Riboli E. Body mass index, abdominal fatness, weight gain and the risk of urinary incontinence: a systematic review and dose-response meta-analysis of prospective studies. BJOG: An International Journal of Obstetrics \& Gynaecology. 2019; 126(12):1424-1433. https://doi.org/10.1111/1471-0528.15897

43. https://tuikweb.tuik.gov.tr/MicroVeri/sagAr_2016/turkce/kilavuz/index.html 